\title{
Sexual dimorphism in histological characteristics and contractility of the iliofibularis muscle in the lizard Sceloporus torquatus
}

\author{
Erendira Quintana, ${ }^{1}$ Javier Manjarrez, ${ }^{2}$ Margarita Martínez-Gómez, ${ }^{3}$ Liliana D’Alba, Jorge Rodríguez- \\ Antolín $^{3}$ and Victor Fajardo ${ }^{1}$
}

\author{
${ }^{1}$ Laboratorio de Conducta Animal, Centro \\ de Investigaciones en Recursos Bióticos- \\ Facultad de Ciencias, Universidad \\ Autónoma del Estado de México, Toluca, \\ Estado de México, 50000, México; \\ ${ }^{2}$ Laboratorio de Biología Evolutiva, Centro \\ de Investigaciones en Recursos Bióticos- \\ Facultad de Ciencias, Universidad \\ Autónoma del Estado de México, Toluca, \\ Estado de México, 50000, México; \\ ${ }^{3}$ Centro Tlaxcala de Biología de la Con- \\ ducta-Universidad Autónoma de Tlaxcala, \\ Unidad Periférica del Instituto de Investi- \\ gaciones Biomédicas, Universidad Nacional \\ Autónoma de México, Tlaxcala, Tlaxcala, \\ 90070, México; ${ }^{4}$ Department of Biology \\ and Integrated Bioscience Program, \\ University of Akron, Akron, Ohio, 44325- \\ 3908, USA
}

Keywords:

Striated muscle, sexual dimorphism, histology, contractility, Sceloporus torquatus lizard

Accepted for publication:

23 November 2012

\begin{abstract}
Quintana, E., Manjarrez, J., Martínez-Gómez, M., D’Alba, L., RodríguezAntolín, J. and Fajardo, V. 2014. Sexual dimorphism in histological characteristics and contractility of the iliofibularis muscle in the lizard Sceloporus torquatus. - Acta Zoologica (Stockholm) 95: 264-271.

The iliofibularis is a hindlimb muscle used in lizard locomotion that is composed of at least three types of fibres: fast-twitch-glycolytic (FG), fast-twitch-oxidativeglycolytic fibre (FOG) and slow-twitch-oxidative (SO). The striated skeletal muscle is a highly plastic tissue undergoing phenotypic change in response to activity. The lizard Sceloporus torquatus has sexual differences associated with microhabitat use, which can be reflected in the physiology and anatomy of the muscle, and thus, in our study, we analysed the morphological and contractile characteristics of the iliofibularis muscle (IF) of $S$. torquatus males and females. We found a larger prevalence of FOG compared with FG and SO fibres in the muscle of both sexes. We also found that males show larger areas of the three types of fibres, develop greater strength but also faster fatigue than females, suggesting that strength is a key functional feature that enables males to perform faster movements (but for shorter periods), associated with the demands of territoriality.

Victor Fajardo, Laboratorio de Conducta Animal, Centro de Investigaciones en Recursos Bióticos-Facultad de Ciencias, Universidad Autónoma del Estado de México, Toluca, Estado de México 50000, México. E-mail: fajardo.vic@gmail. com
\end{abstract}

\section{Introduction}

As in other vertebrates, the striated skeletal muscle of lizards is composed of at least three types of fibres, classified according to their metabolic and contractile properties as slow-twitch, oxidative (SO) with a high lipid content, fast-twitch, glycolytic (FG) with a lower lipid content, and fast-twitch, oxidative-glycolytic fibre (FOG) with intermediate lipid content (Close 1972; Peter et al. 1972).

The striated skeletal muscle is a highly plastic tissue that changes phenotypically in response to activity level, temperature, circulating hormone concentrations, growth and development (Salmon and Vrbova 1969; Pette and Staron 2001; Goldspink 2002). These phenotypic changes can include muscle size increase or decrease (atrophy or hypertrophy) and modifications of the composition of fibre types
(Buller et al. 1960; Boonyarom and Inui 2006). Sexual dimorphism in physiological properties of the striated muscles, such as enzymatic activity, contractile performance and fibre type composition, can correlate with behavioural traits of each sex (Boyd et al. 1999; Peters and Aulner 2000; Schultz et al. 2001; Girgenrath and Marsh 2003). For example, sex differences have been reported in striated muscles that participate in sexually dimorphic behaviours like in those associated with sound production in frogs and birds and in muscles of throat fan extension in lizards (see Rosen et al. 2004).

The Sceloporus genus presents sex differences in habitat use, behaviour, limb length and consequently in locomotor performance. $S$. torquatus males occupy and defend territories against conspecifics and spend most of their time on rocks, whereas females are generally active foragers on the ground, on grassy areas far from rocks (Hunsaker 1969; Ferguson 
1971; Feria et al. 2001; Herrel et al. 2002; Smith and LemosEspinal 2005). Accordingly, females of this species are expected to show higher levels of activity compared with males, which may result in differences in histological characteristics and contractile properties of locomotor muscles like the iliofibularis muscle (IF). The IF has been extensively studied in lizards (e.g. Gleeson et al. 1980; Putnam et al. 1980; Bonine et al. 2001, 2005; Scales et al. 2009; Higham et al. 2011). It is a unipennate muscle, an abductor of the hindlimb and spans both the knee and hip joint. It is responsible for flexing the knee during the swing phase (when the limb is off the ground) in constant speed and burst locomotion (Jayne et al. 1990 cited in Bonine et al. 2005). Therefore, the contractile properties of the IF may reflect sprint speed ability and fatigue resistance in lizards (Bonine et al. 2005).

The aim of this study was to compare the histological characteristics and contractile properties of IF of males and females of $S$. torquatus lizard.

\section{Materials and Methods}

All procedures were approved by the Ethics Committee of the Universidad Autónoma de Tlaxcala, and the guidelines for the use of animals in research from the Centro de Investigaciones en Recursos Bióticos-Facultad de Ciencias, Universidad Autónoma del Estado de México were followed throughout.

\section{Animals}

Twenty Sceloporus torquatus lizards were used in this study: ten females and ten males. Lizards were captured at Cerro de Coatepec, Toluca, State of México (19 ${ }^{\circ} 16^{\prime} 59^{\prime \prime} \mathrm{N}, 99^{\circ} 40^{\prime}$ $40^{\prime \prime}$ W) at an altitude of 2727 m.a.s.1. from December 2009 to January 2010 and transported to the Laboratory of Fisiología de la Conducta del Centro Tlaxcala de Biología de la Conducta (CTBC-UNAM).
Animals were anesthetized with ketamine (70 mg ip / $\mathrm{kg}$ body weight), and after measuring the contractile properties, they were euthanized with an overdose of anaesthetic via intracardiac infusion. The IF of the right limb was used in the muscle twitch tests, and the IF of the left limb was used to prepare the histological description.

\section{Contractile properties}

Anesthetized animals were placed in a dorsal supine position, the right limb was fixed in an angle of $90^{\circ}$ between the thigh and the calf (Fig. 1A), and under a surgical microscope (magnification $\times 16 \times$, Nikon, model SMZ-2T, Japan), the muscles were exposed, measured, severed at their insertion, separated from the surrounding tissue (except blood supply) and the tendons were attached to a tension transducer with surgical silk (Grass, model FT03E, USA) to measure the contractile force expressed in grams (Fig. 1B). All experimental procedures were performed at $28-30{ }^{\circ} \mathrm{C}$ of muscle temperature (Marsh and Bennett 1986) using a red lamp. Muscles were kept under constant irrigation of a sodium chloride solution $(0.09 \%)$.

To record the muscle contractile properties, we follow the protocol described by Fajardo et al. (2008), first we obtained the optimal stimulation intensity of muscle response and then we eliminated the influence of the muscle elastic components like tendons and connective tissue (see below).

Optimal stimulation intensity of muscle response. When the muscle was attached to the tension transducer, they were stretched until reaching the length observed in the intact leg. After this, the muscles were stimulated using a pulse generator (Grass model S48, USA) connected to two-wire silver electrodes attached to the lateral sides of the muscles (Fig. 1B). The stimulation intensity was gradually increased to obtain the
Fig. 1-A. A schematic representation of how the muscle was measured: the right limb was fixed at a $90^{\circ}$ angle between the thigh and the calf. B. The exposed muscle was attached to a tension transducer with surgical silk.
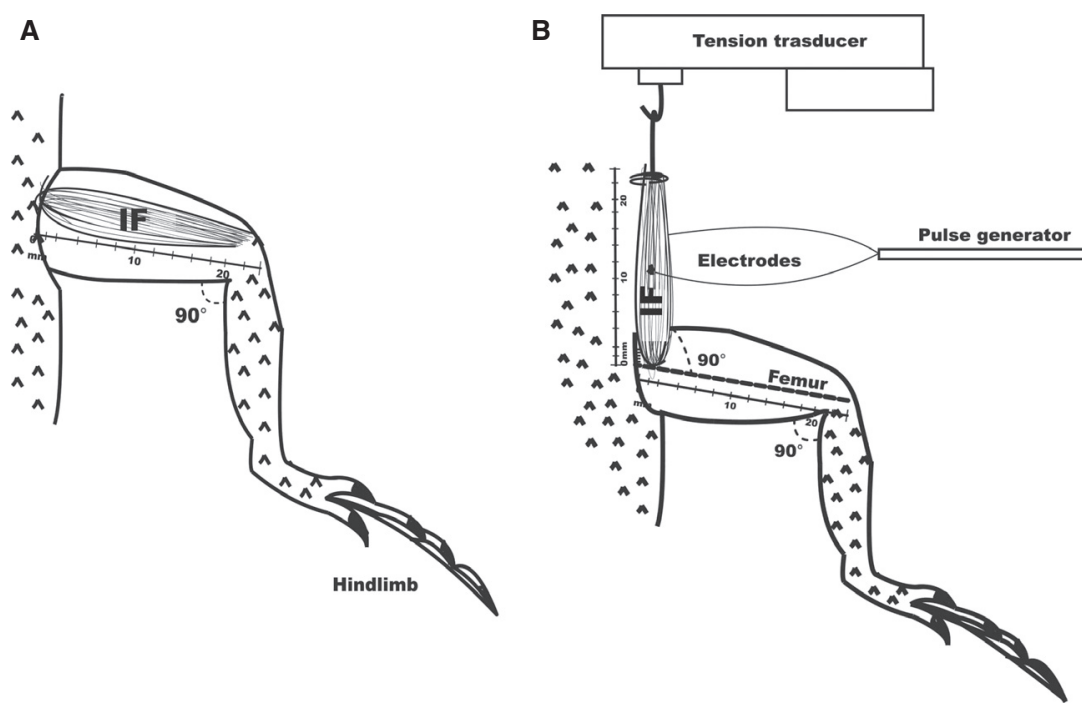
maximum muscle response $(3-5$ stimuli of $1 \mathrm{~Hz} ; 0.5$ min s duration, 5-s inter-stimulation).

Elimination of muscle elastic component effects. Once we obtained the optimal stimulation intensity of muscle response, the muscles were stretched to find the optimum length necessary to generate the maximum response and to control for the effect of elastic components in the muscle (tendon and connective tissue). Single, square electrical pulses ( $3-5$ stimuli $1 \mathrm{~Hz}$; 0.5 min s duration, 5-s inter-stimulation) were used to produce individual muscle twitches.

Protocol of muscle contractile properties. We used square electrical stimulus trains of ascending frequency $(1-30 \mathrm{~Hz}$; 3-s duration, 5-s inter-stimulation) to cause the fusion of muscle responses (tetanus). In the pilot test, we measured the fusion frequency to be $30 \mathrm{~Hz}$, hence, this was the tetanus frequency used throughout the study. We measured the twitch/tetanus force ratio ( $\mathrm{t}-\mathrm{T}$ ratio), and to control for the effect of muscle size, we calculated the force per unit cross-sectional area (simple twitch/muscle cross-sectional area and tetanus/muscle cross-sectional area), which is expressed in grams-force $/ \mathrm{cm}^{2}$. In addition, a $30-\mathrm{Hz}$ stimulus train for $10 \mathrm{~s}$ was used to determine the fatigability index ( $\%$ difference in force measured at the initial peak and at the end of the plateau phase of the response).

Responses were recorded on a polygraph (Grass, model 7S1, USA) and stored in a PC (Dell, model Dimension 4800, USA) using Polyview software (2.5 for Windows, Astro-Med Inc, USA).

\section{Histology}

Sudan black staining. Using the method described by Fajardo et al. (2008) and under a surgical microscope (magnification $16 \times$, Nikon, model SMZ-2T, USA), the muscles of five females and five males were exposed and dissected out. The muscles were placed in a solution of $10 \%$ formaldehyde, $0.1 \%$ cobalt nitrate and $10 \%$ calcium chloride for four weeks and cryoprotected for $24 \mathrm{~h}$ in a solution of $40 \%$ sucrose containing $0.1 \mathrm{M}$ sodium phosphate $(\mathrm{pH} 8.0)$.

Before staining, the muscles were embedded in TissueTek OCT Compound (Sakura Finetek, Torrance, California, USA), cut in 16- $\mu \mathrm{m}$ cross-sections in a cryostat (Leica, model CM1850, Germany) and the sections were mounted on gelatinized slides. We used a modification of the Sudan Black lipid-staining technique (Humason 1979) to distinguish between the high lipid-content SO and the lower lipid-content fibres FG and FOG as described by Fajardo et al. (2008).

$N A D H$ staining. We used the IF of five females and five males of $S$. torquatus to analyse by NADH-D reactivity. NADHdiaphorase activity was determined by a method adapted from Novikoff et al. (1961). Sections were incubated for $1 \mathrm{~h}$ in a solution containing $1 \mathrm{mM}$ NADH, $1 \mathrm{mM}$ nitro-blue tetrazolium, $100 \mathrm{mM}$ phosphate buffer ( $\mathrm{pH} \mathrm{7.6)}$; washed $5 \mathrm{~min}$ in running tap water, fixed 5 min in $10 \%$ formalin; dehydrated, cleared and mounted in Permount.

\section{Image analysis}

Ten transversal and sequential cross-sections from the middle portion of each muscle were selected. We photographed four fields of each section (magnification $\times 40$; bottom and top left and right side) using a light microscope (Olympus, model BX41TF, Japan) and a digital camera system with detail enhancement (Olympus, model E-330, Japan). This allowed us to visualize the complete muscle. Images were transferred via firewire interface cable (IEEE 1394 DV) to a PC (Dell precision T3400, USA). We analysed images following a modification of the protocol described by Fajardo et al. (2008). We used Sigma Scan Pro software (version 4 for Windows, Systat Software Inc, USA) after converting images into an eight-bit grey scale (256 shades).

We determined the cross-sectional area and density of stain of each muscle fibres from digitized micrographs using the Sigma Scan Pro software (version 4 for Windows, Systat Software Inc, USA).

Fibres were classified as FG (shades 136-255 on the grey scale from the Sudan Black staining and from NADH-D staining shades 0-120), FOG (from 101 to 135 in Sudan Black staining and from NADH-D staining shades 121-145) and SO (from 0 to 100 from the Sudan Black staining and from NADH staining shades 146-255). For Sudan Black image analysis and calibration, we used droplets of lizard fat as control, because they stained dark with a density from 0 to 20 shades on the grey scale, and for NADH-D image analysis and calibration, we used the SO fibres as controls, because they stained dark with a density of 0-35 shades on the grey scale (Fajardo et al. 2008). Additionally, we obtained the entire muscle cross-sectional area using digitized images (magnification $\times 10$ ) and the Sigma Scan Pro software (version 4 for Windows, Systat Software Inc, USA).

\section{Statistical analysis}

For the comparison of the cross-sectional area of each fibre type, we used a one-way ANOVA. For comparison between sex and cross-sectional fibre area, we used a nested ANOVA, using values of fibre area nested within fibre type. In both analyses, we used the Tukey-Kramer post hoc tests to identify the nature of any statistical differences (JMP software, version 4 for Windows, SAS Institute Inc., USA). For the comparison of the percentage of fibre types between sexes and between fibre types on each stain (Sudan Black versus NADH-D staining), we used a chi-square analysis (GB-STAT for Windows, USA). Because the data did not follow a normal distribution, the Mann-Whitney U-tests were used to compare contractile properties, the muscle cross-sectional area and the number of fibres in each muscle between males and females (Statistics software, version 7 for Windows, StatSoft Inc., 
Table 1 Means \pm standard deviations of the four variables measured in the specimens of Sceloporus totquatus of each sex

\begin{tabular}{lcc}
\hline & \multicolumn{1}{l}{ Male } & \multicolumn{1}{l}{ Female } \\
\hline BM (g) & $23.0 \pm 2.6$ & $16.4 \pm 2.1^{\star}$ \\
SVL (mm) & $91 \pm 5$ & $87 \pm 8$ \\
IFL (mm) & $24.2 \pm 3.2$ & $22.6 \pm 1.6$ \\
IFM (g) & $0.0728 \pm 0.0050$ & $0.0407 \pm 0.0052^{\star *}$ \\
\hline
\end{tabular}

BM, body mass; SVL, snout-vent length; IFL, iliofibularis muscle length; IFM, iliofibularis muscle mass. The BM and IFM showed statistical differences between sexes, BM $\left(U_{10,10}=2,{ }^{*} P<0.05\right)$ and IFM $\left(t_{18}=4.52,{ }^{* \star} P<0.001\right)$.

USA). All tests were two-tailed, and a $P<0.05$ was taken as the least significance level. All values presented are mean \pm SD unless otherwise stated.

\section{Results}

Animals

The morphometric data of the animals used in this study are resumed in the Table 1

\section{Histological}

We identified three different types of muscle fibres in the IF of the Sceloporus torquatus. They were classified as SO, FG and FOG (Fig. 2). In both sexes, the cross-sectional areas of FOG fibres were larger compared with SO and FG fibres' cross-sectional areas (males: $F_{2}=389.08, P<0.001$ and females: $F_{2}=572.50, P<0.001$; Fig. 3). When comparing between sexes, males showed larger cross-sectional areas of the three types of fibres than females $\left(F_{2}, 1458=31.14, P<0.001\right.$; Fig. 3).

As previously reported by Putnam et al. (1980), the IF has two clearly defined regions, the white and red regions. In males of our study, the white region of the IF was $21-$ $26 \%$ of the IF total cross-area, and it is composed of $2-3 \%$ of SO, $70-72 \%$ of FG and $25-27 \%$ of FOG fibres. The red region is composed completely of FOG fibres (Fig. 4). The total number of fibres that compose the IF in males was $1270 \pm 35$.

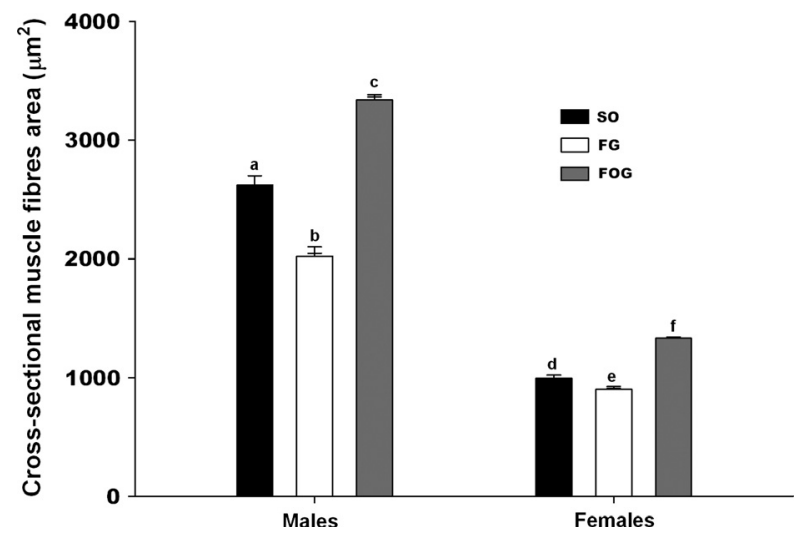

Fig. 3-Cross-sectional area (Mean $\pm \mathrm{SD}$ ) of SO, FG and FOG fibre types of the iliofibularis muscle of male and female lizards. In all cases females had smaller muscle cell areas $(P<0.001$, two-way ANOVA and Tukey-Kramer post hoc test).

In females, the white region comprises $19-25 \%$ of the IF total cross-area, with a composition of $5-6 \%$ of SO, $70-73 \%$ of FG and $26-29 \%$ of FOG. As in males, the red region is constituted solely by FOG fibres (Fig. 4). The total number of fibres that compose the IF in females was $1220 \pm 16$. There were no significant differences between the stains (females $X^{2}=0.49$, $\mathrm{df}=2, P=0.78$ and males $X^{2}=0.43$, $\mathrm{df}=2, P=0.80)$, and no sex differences in the overall proportion $\left(X^{2}=1.256, \mathrm{df}=2, P=0.53\right)$ or total number of fibres $\left(U_{10,10}=6.5, P=0.143\right)$ that compose the IF were found.

Interestingly, however, the proportion of SO fibres in the white region of females was significantly larger than SO fibres in males $\left(U_{10,10}=25, P<0.05\right)$. We also found that males showed larger cross-sectional areas of the whole muscle compared with females $\left(U_{10,10}=36, P<0.05\right.$; Fig. $\left.5 \mathrm{~A}\right)$.

\section{Contractile properties}

The IF developed significantly more force in males during simple twitches $\left(U_{10,10}=18, P<0.05\right)$ and tetanus $\left(U_{10,10}=12, P<0.05\right)$ than in females (Figs. 6 and 7 ), which was consistent with the larger cross-sectional fibre area in males (Fig. 3). Males showed a significantly higher fatigability index than females $\left(U_{10,10}=6, P<0.05\right.$; Fig. 6).
Fig. 2-Photomicrographs of the iliofibularis muscle in the lizard Sceloporus torquatus. Note the different types of fibres A. Sudan Black Staining B. NADH Staining.
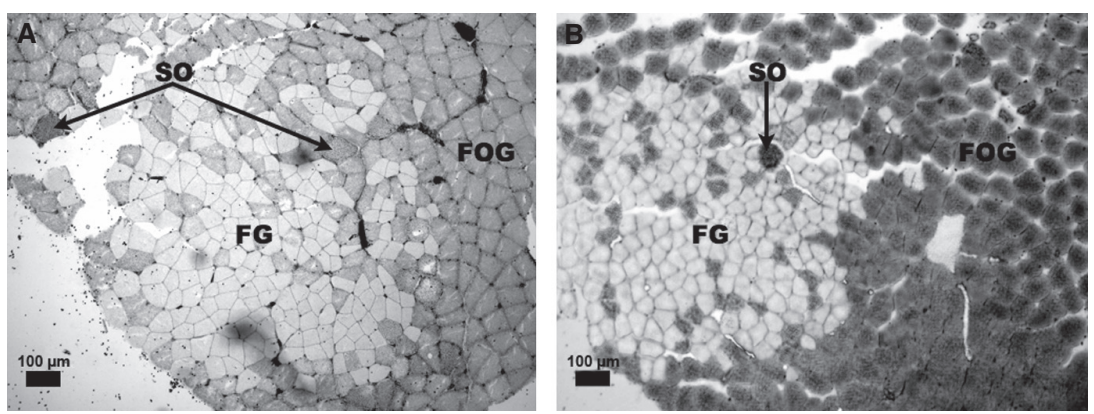


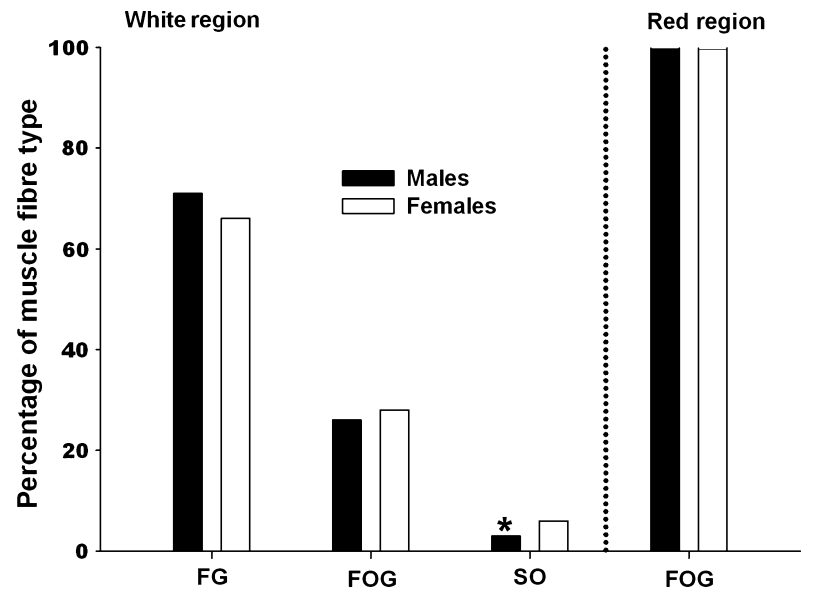

Fig. 4 - Percentage of fibre types in the white and red region of Iliofibularis muscle of Sceloporus torquatus. In the white region the percentage of SO fibres in females was greater than in males $(* P<0.05$, Mann-Whitney $U$-test).

Finally, we found that males exerted significantly greater force per unit cross-sectional area than females $\left(U_{10,10}=12\right.$, $P<0.05$; Fig. 5B).

\section{Discussion}

This is the first study describing sexual dimorphism in fibre type composition and IF contractility in Sceloporus torquatus. We showed that even when males and females do not differ in body size or IF length, males present larger cross-sectional areas of the three fibre types than females. This is not due to an increased number of fibres in males but a larger fibre size than those of females. Also, the force developed by males even in the force by cross-sectional area is higher than that developed by females but males showed higher muscle fatigue compared with females.
As previously reported for the Sceloporus group (Bonine et al. 2001, 2005), we found that the IF in S. torquatus is composed of SO, FG and FOG fibres. Additionally, in both males and females, the IF is composed predominantly of FOG fibres, which are associated with relatively fast longduration movements, followed by FG fibres, and to a lesser extent SO fibres. This is consistent with other studies on this genus, which is considered to have intermediate locomotor speed, different from the Uma, Callisaurus, Cophosaurus and Holbrookia genera, which are considered sprinters and the Phrynosoma genus, classified as slow runners (Bonine et al. 2001, 2005).

Interestingly, females presented lower IF fatigability than males. Female mammals are known to have a greater muscle fatigue resistance than males, which has been associated with higher concentrations of oestradiol (Tiidus 2000; Hicks et al. 2001; Brown 2008). Females in our study most likely were in post-reproductive season (Mendez-de la Cruz and GutiérrezMayén 1991). Indeed, all the females in our sample had embryos in their oviducts. Oestradiol is found in conjugate and unmetabolized forms in the striated muscle of gestating lizard females (Edwards et al. 2005), and thus, the female lower fatigability index could be related to the oestradiol levels (Tiidus 2000; Hicks et al. 2001; Brown 2008).

On the other hand, there is evidence that under ischaemic conditions, the low fatigue of mammal female striated muscle ceases, suggesting that the sex differences in fatigue are bloodflow dependent (Hogan et al. 1994; Russ and Kent-Braun 2003). In our study, we did not measure the muscle capillarity but the IF blood flow was maintained throughout the study, ensuring that oxygen delivery was kept constant. It is possible then that in females, FOG fibres metabolize oxygen more effective than in males, explaining the observed low fatigability index. Moreover, although the proportion of each fibre type did not differ between sexes, females did have a higher frequency of the SO fibres in the IF white region (males, 8-10 fibres and females, 20-23 fibres). SO fibres are associated

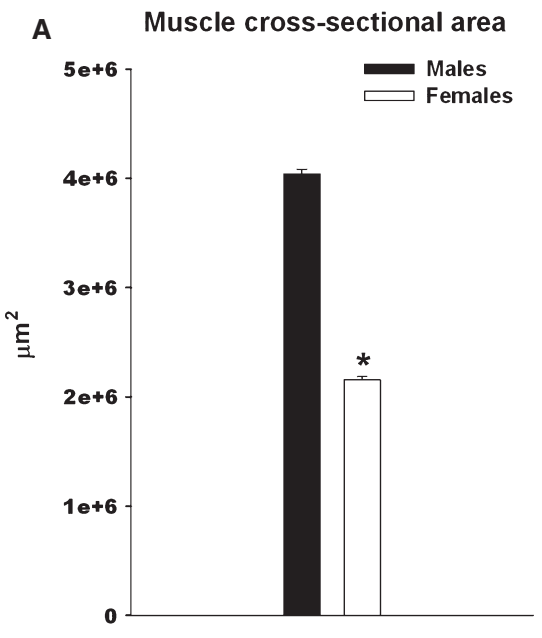

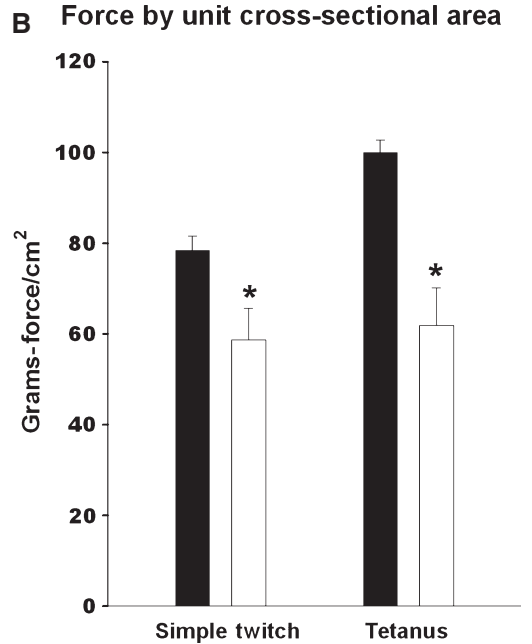

Fig. 5-A) Muscle cross-sectional area (Means $\pm \mathrm{SD}$ ) of the iliofibularis muscle in the lizard Sceloporus torquatus $\left({ }^{*} P<0.05\right.$, Mann-Whitney $U$-test) and B) Force developed by the iliofibularis muscle by unit crosssectional area in males and female lizards $\left({ }^{*} P<0.05\right.$, Mann-Whitney $U$-test). 
Fig. 6-Contractile properties (Means \pm SD) of iliofibularis muscle. The force developed by males was greater than females during simple twitch and tetanus obtained at $30 \mathrm{~Hz}$. ( ${ }^{*} P<0.05$, Mann-Whitney $U$-test). t-T ratio $=$ twitch/tetanus. The males showed greater fatigability index than females.
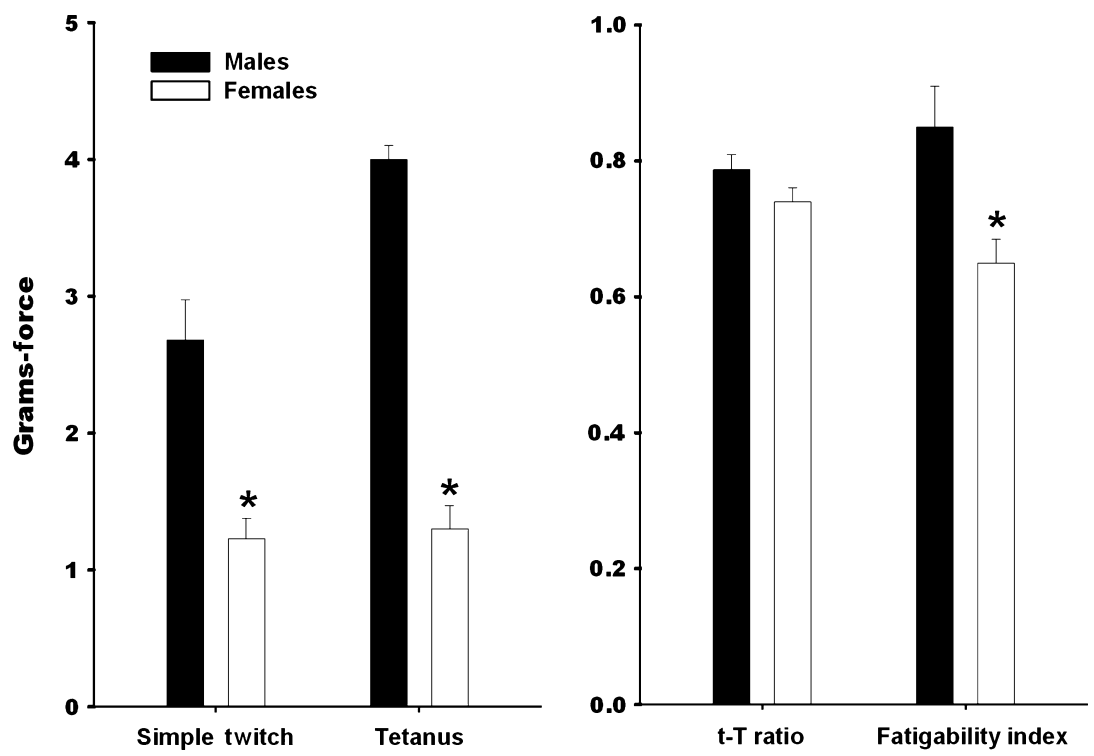

with slow-speed locomotion and high endurance (Gleeson et al. 1980; Putnam et al. 1980). Thus, a higher frequency of SO fibres in females could contribute to the lower fatigability index observed in our study.

In addition to the herein described fibre types, a fourth muscle fibre type (tonic fibres) has been recognized in the red region of IF of lizards (e.g., Dipsosaurus dorsalis), which has been associated with slow contraction (Gleeson et al. 1980; Putnam et al. 1980). In some terrestrial vertebrates, the tonic fibres have been implicated in limb deceleration and postural support; similar functions have been suggested in lizards (Putnam et al. 1980). Thus, it is possible that these types of muscle fibres contribute to the observed fatigability of IF, but unfortunately, in this study, we could not distinguish the tonic fibres. More exhaustive studies on the metabolism of muscle fibres between the sexes are necessary to determine the exact causes of lower fatigability index in $S$. torquatus females.

The IF in males of $S$. torquatus generated greater strength than in females even when we compared the force by crosssectional area. The characteristics of the striated muscle are influenced by sexual hormones. For example, testosteroneinduced increase in muscle size and strength is associated with muscle fibre hypertrophy (Bhasin et al. 2001; Boff 2008). Sexual hormones may be related to the differences found in size and contractile properties of the fibres between sexes as was described for Rana catesbeiana and Anolis carolinensis in which the muscles differ in their histology and contractile properties within the breeding season (Peters and Aulner 2000; Holmes et al. 2007), but the role of sexual hormones on the locomotion of lizard muscles is not completely clear

Fig. 7-Simple twitch and tetanus response of iliofibularis muscle. The measured force was higher in males than females.

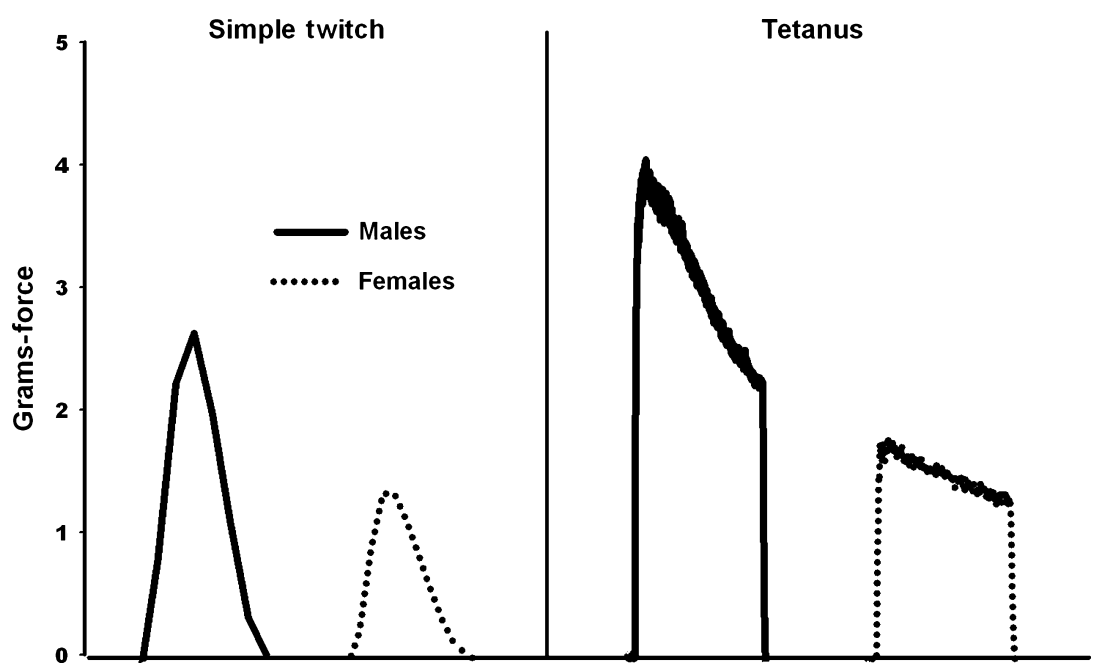


(O'Bryant and Wade 2002; Holmes et al. 2007; Huyghe et al. 2010). This question still challenges our understanding of muscle physiology in lizards.

The Sceloporus genus has a wide variety of morphologies, habitat use, locomotor performance and behavioural patterns, even between sexes (Bonine et al. 2001; Feria et al. 2001; Herrel et al. 2002; Smith and Lemos-Espinal 2005). It has been suggested that in lizards, foraging and predator-escape behaviour are the main causes of diversity in morphology and locomotor performance (Miles et al. 2000; Verwaijen and Van Damme 2007; Scales et al. 2009), which may explain the differences in histological characteristics and contractile properties of the muscle we found in this study. In natural conditions, $S$. torquatus has sex differences in microhabitat use, foraging and escaping behaviours (Hunsaker 1969; Feria et al. 2001). Males are territorial and spend most of the time on rocks, which are their territories, but that makes them more visible to predators and prey, so they require fast movement for foraging and escape. Besides, males do not move long distances because their territory is limited by both the area and sheltering cracks in the rock; furthermore, the male muscles showed greater strength but they are more prone to fatigue, maybe because males depend on speed and not resistance in the runs for foraging and escape (McElroy et al. 2006).

We have observed that females are generally active foragers on the ground far from rocks (personal observations). They must run long distances to escape from their predators. Females may require high-sustained force and therefore may need to show higher fatigue resistance ability than males. This could be reflected in the higher percentage of SO fibres in the IF. Contrary to our findings, two previous studies in lizards found no sex differences in muscle fatigue related to locomotor performance (Cullum 1998; Van Damme et al. 2008). Further studies are needed to investigate individual muscle contractile properties and histological characteristics of all muscles that make up the hindlimbs in lizards; this will provide a better understanding of the differences in locomotor performance between sexes and the variation associated with seasonal and reproduction status (Shine 1980; Van Damme et al. 1989; Miles et al. 2000).

In conclusion, our results and observations support the idea that muscle characteristics are coadaptations of organisms and environment, as noted by Bonine et al. (2001). What we need to know now is whether and how the environment affects the relationship between muscle phenotype and fitness. Therefore, studies on habitat, behavioural patterns, morphological characteristics and locomotor performance are needed to better understand the plasticity of the locomotor muscles.

\section{Acknowledgements}

The authors are grateful to Biol. Ivan Contreras for his excellent help in collecting data and search for bibliography, to
SEMARNAT for the permission to use the animals and to CONACYT EQS 226935/212661 for the funding and helpful comments from anonymous reviewers improved this manuscript.

\section{References}

Bhasin, S., Woodhouse, L. and Storer, T.W. 2001. Proof of the effect of testosterone on skeletal muscle. Fournal of Endocrinology 170: 27 38.

Boff, S.R. 2008. The muscle fiber and the factors that interfere with its phenotype. Acta Fisiatrica 15: 111-116.

Bonine, K.E., Gleeson, T.T. and Garland, T. 2001. Comparative analysis of fiber type composition in the iliofibularis muscle of phrynosomatid lizards. Fournal of Morphology 250: 265-280.

Bonine, K.E., Gleeson, T.T. and Garland, T. 2005. Muscle fibertype variation in lizards (Squamata) and phylogenetic reconstruction of hypothesized ancestral states. Fournal of Experimental Biology 208: 4529-4547.

Boonyarom, O. and Inui, K. 2006. Atrophy and hypertrophy of skeletal muscles: structural and functional aspects. Acta Physiologica 188: $77-89$.

Boyd, S.K., Wissing, K.D., Heinsz, J.E. and Prins, G.S. 1999. Androgen receptors and sexual dimorphisms in the larynx of the bullfrog. General Comparative Endocrinology 113: 59-68.

Brown, M. 2008. Skeletal muscle and bone: effect of sex steroids and aging. Advances in Physiology Education 32: 120-126.

Buller, A.J., Eccles, J.C. and Eccles, R.M. 1960. Interactions between motoneurons and muscles in respect of the characteristic speeds of their responses. Fournal of Physiology 150: 417-439.

Close, R.I. 1972. Dynamic properties of mammalian skeletal muscles. Physiological Reviews 52: 129-197.

Cullum, A.J. 1998. Sexual dimorphism in physiological performance of Whiptail Lizards (Genus Cnemidophorus). Physiological Zoology 71: 541-552.

Edwards, A., Jones, S.M. and Davies, N.W. 2005. Patterns of peripheral steroid metabolism vary with sex, season, and tissue type in blotched blue-tongued lizards (Tiliqua nigrolutea). General and Comparative Endocrinology 140: 14-24.

Fajardo, V., Pacheco, P., Hudson, R., Jimenez, I. and MartinezGómez, M. 2008. Differences in morphology and contractility of the bulbospongiosus and pubococcygeus muscles in nulliparous and multiparous rabbits. International Urogynecology fournal 19: 843-849.

Ferguson, G.W. 1971. Observations on the behavior and interactions of two sympatric Sceloporus in Utah. The American Midland Naturalist fournal 86: 190-196.

Feria, O.M., Nieto-Montes de Oca, A. and Salgado-Ugarte, I.H. 2001. Diet and reproductive biology of the viviparous lizard Sceloporus torquatus torquatus (Squamata: Phrynosomatidae). Fournal of Herpetology 35: 104-112.

Girgenrath, M. and Marsh, R.L. 2003. Season and testosterone affect contractile properties of fast calling muscles in the gray tree frog Hyla chrysoscelis. American fournal of Physiology. Regulatory Integrative and Comparative Physiology 284: R1513-R1520.

Gleeson, T.T., Putnam, R.W. and Bennett, A.F. 1980. Histochemical, enzymatic, and contractile properties of skeletal muscle fibers in the lizard Dipsosaurus dorsalis. Fournal of Experimental Zoology 214: 293-302.

Goldspink, G. 2002. Gene expression in skeletal muscle. Biochemical Society Transactions 30: 285-290. 
Herrel, A., Meyers, J.J. and Vanhooydonck, B. 2002. Relations between microhabitat use and limb shape in phrynosomatid lizards. Biological fournal of the Linnean Society 77: 149-163.

Hicks, A.L., Kent-Braun, J. and Ditor, D.S. 2001. Sex differences in human skeletal muscle fatigue. Exercise and Sport Sciences Reviews 293: 109-112.

Higham, T.E., Korchari, P.G. and McBrayer, L.D. 2011. How muscle define maximum running performance in lizard: an analysis using swing- and stance-phase muscles. Fournal of Experimental Biology 214: 1685-1691.

Hogan, M.C., Richardson, R.S. and Kurdak, S.S. 1994. Initial fall in skeletal muscle force development during ischemia is related to oxygen availability. Fournal of Applied Physiology 77: 2380-2384.

Holmes, M.M., Bartrem Casey, L. and Wade, J. 2007. Androgen dependent seasonal changes in muscle fiber type in the dewlap neuromuscular system of green anoles. Physiology \& Behavior 91: 601-608.

Humason, G. 1979. Animal Tissue Techniques. Freeman, USA.

Hunsaker 11, D. 1969. Ethological isolating mechanisms in the Sceloporus torquatus group of lizards. Evolution 16: 62-74.

Huyghe, K., Husak, J.F., Moore, I.T., Vanhooydonck, B., Van Damme, R., Molina-Borja, M. and Herrel, A. 2010. Effects of testosterone on morphology, performance and muscle mass in a lizard. Fournal of Experimental Zoology 313A: 9-16.

Jayne, B.C., Bennett, A.F. and Lauder, G.V. 1990. Muscle recruitment during terrestrial locomotion: how speed and temperature affect fiber type used in a lizard. Fournal of Experimental Biology 152: 101-128.

Marsh, R.L. and Bennett, A.F. 1986. Thermal dependence of sprint performance of the lizard Sceloporus occidentals. Fournal of Experimental Biology 126: 79-87.

McElroy, E.J., Meyers, J.J., Reilly, S.M. and Irschick, D.J. 2007. Dissecting the effects of behaviour and habitat on the locomotion of a lizard (Urosaurus ornatus). Animal Behaviour 73: 359365.

Mendez-de la Cruz, F.M. and Gutiérrez-Mayén, M.G. 1991. Variación de la robustez física de Sceloporus torquatus (Sauria: Iguanidae) y sus implicaciones sobre la temporada de reproducción. Acta Zoológica Mexicana 46: 1-12.

Miles, D.B., Sinervo, B. and Frankino, A.W. 2000. Reproductive burden, locomotor performance, and the cost of reproduction in free ranging lizards. Evolution 54: 1386-1395.

Novikoff, A.B., Shin, W. and Drucher, J. 1961. Mitochondrial localization of oxidative enzymes: staining results with two tetrazolium salts. Fournal Biophysical and Biochemical Cytology 9: 4761.

O'Bryant, E.L. and Wade, J. 2002. Sexual dimorphisms in a neuromuscular system regulating courtship in the green anole lizard: effects of season and androgen treatment. Fournal of Neurobiology 402: 202-213.

Peter, J.B., Barnard, R.J., Edgerton, V.R., Gillespie, C.A. and Stemple, K.E. 1972. Metabolic profiles of three fiber types of skeletal muscle in guinea pigs and rabbit. Biochemistry 11: 2627-2633.

Peters, S.E. and Aulner, D.A. 2000. Sexual dimorphism in forelimb muscles of the bullfrog, Rana catesbeiana: a functional analysis of isometric contractile properties. Fournal of Experimental Biology 203: 3639-3654.

Pette, D. and Staron, R.S. 2001. Transitions of muscle fiber phenotypic profiles. Histochemistry and Cell Biology 115: 359-372.

Putnam, R.W., Gleeson, T.T. and Bennett, A.F. 1980. Histochemical determination of the fiber composition of locomotory muscle in a lizard, Dipsosaurus dorsalis. Fournal of Experimental Zoology 214: 303-309.

Rosen, G.J., O'Bryant, E.L., Swender, D. and Wade, J. 2004. Fiber type composition of the muscle responsible for throat fan extension in green anole lizard. Brain Behavior and Evolution 64: 34-41.

Russ, D.W. and Kent-Braun, A. 2003. Sex differences in human skeletal muscle fatigue are eliminated under ischemic conditions. Fournal of Applied Physiology 94: 2414-2422.

Salmon, S. and Vrbova, G. 1969. The influence of activity on some contractile characteristics of mammalian fast and slow muscles. Fournal of Physiology 201: 535-549.

Scales, J.A., King, A.A. and Butler, M.A. 2009. Running for your life or running for your dinner: what drives fiber-type evolution in lizard locomotor muscles?. The American Naturalis 173: 543-553.

Schultz, J.D., Hertel, F., Bauch, M. and Schlinger, B.A. 2001. Adaptations for rapid and forceful contraction in wing muscles of the male golden-collared manakin: sex and species comparisons. Fournal of Comparative Physiology 187: 677-684.

Shine, R. 1980. 'Costs' of reproduction in reptiles. Oecologia 46: 92100.

Smith, G.R. and Lemos-Espinal, J.A. 2005. Comparative escape behavior of four species of Mexican phrynosomatid lizards. Herpetologica 6: 225-232.

Tiidus, P.M. 2000. Estrogen and gender effects on muscle damage, inflammation, and oxidative stress. Canadian fournal of Applied Physiology 25: 274-287.

Van Damme, R., Bauwens, D. and Verheyen, R.F. 1989. Effect of relative clutch mass on sprint speed in the lizard Lacerta vivipara. fournal of Herpetology 23: 459-461.

Van Damme, R., Entin, P., Vanhooydonck, B. and Herrel, A. 2008. Causes of sexual dimorphism in performance traits: a comparative approach. Evolutionary Ecology Research 10: 229-250.

Verwaijen, D. and Van Damme, R. 2007. Does foraging mode mould morphology in lacertid lizards?. Fournal of Evolutionary Biology 20: 1950-1961. 